\title{
Sensory profile development of Oaxaca cheese and relationship with physicochemical parameters
}

\author{
J. Sandoval-Copado, ${ }^{*}$ J. Orozco-Villafuerte, ${ }^{*}$ D. Pedrero-Fuehrer, $†$ and M. A. Colín-Cruz ${ }^{* 1}$ \\ *Departamento de Alimentos, Facultad de Química, Universidad Autónoma del Estado de México, Toluca, 50120, Mexico \\ †Pentasensorial Co., Mexico City, Mexico 03100
}

\begin{abstract}
A sensory profile of Oaxaca cheese was developed. To represent both industrial and artisanal Oaxaca cheese, 3 types of cheese were manufactured under controlled conditions: 2 with pasteurized milk using a mesophilic lactic acid bacteria culture (Lactococcus lactis ssp. lactis and L. lactis ssp. cremoris) and a thermophilic lactic acid bacteria culture (Streptococcus salivarius ssp. thermophilus), and a third with naturally acidified raw milk. The cheeses were evaluated by a panel of 11 trained judges. Additionally, chemical composition and instrumental color parameters were determined, an instrumental texture profile analysis was performed, and volatile compounds were identified by solid-phase microextraction coupled with gas chromatography/mass spectrometry. The sensory profile developed includes 43 descriptors, of which 13 are discriminant among these 3 cheese types. Descriptors include visual attribute waxy; tactile (manual) attributes moist and oily; orthonasal aroma attributes empyreumatic and cow; basic taste attribute salty; mouth texture attributes chewable, gummy, adherent, fibrous, moist, and fatty; and auditory attribute squeaky. A strong correlation was found between specific sensory data and physicochemical parameters measured by instrumental and chemical methods.
\end{abstract}

Key words: descriptive analysis, pasta filata cheese, solid-phase microextraction coupled with gas chromatography/mass spectrometry, texture profile analysis

\section{INTRODUCTION}

Oaxaca cheese, a fresh pasta filata cheese of Mexican origin, is manufactured throughout Mexico, industrially and in artisanal form. It is used as an ingredient in diverse traditional Mexican dishes that make good use of

Received December 28, 2015.

Accepted May 27, 2016.

${ }^{1}$ Corresponding author: macolinc@uaemex.mx its melting properties. Artisanal Oaxaca cheese is made from raw milk, naturally acidified by the microflora present in milk, whereas the industrial product is made with pasteurized milk, acidified with commercial lactic acid bacteria (LAB). A mixture of Lactococcus is used, although Streptococcus salivarius ssp. thermophilus is preferred due to its greater acidifying activity; direct acidification is also used. Because of its cultural, nutritional, gastronomical, and economic importance, there is a growing interest in studying the physicochemical, microbiological, functional, and structural characteristics of Oaxaca cheese (Montes de Oca-Flores et al., 2009; Colín-Cruz et al., 2012; Caro et al., 2013).

Regarding sensory characteristics, Villanueva-Carvajal et al. (2012) analyzed 11 artisanal Oaxaca cheeses and defined a flavor profile formed by 14 attributes, finding that certain sensory attributes were correlated with adherence, cohesiveness, and springiness as measured by a texturometer [texture profile analysis (TPA)]. Montes de Oca-Flores et al. (2012), analyzed 11 artisanal Oaxaca cheeses produced in the highlands of Mexico and established a profile of flavor and aroma, composed of 8 attributes: creamy, fresh, salty milk, whey, pasteurized milk, sour, yeast, and powdered milk. The panel found significant differences only in the attributes sour and pasteurized milk. Fuentes et al. (2015) evaluated microbiological, physicochemical, and sensory quality in 3 artisanal Oaxaca cheeses placed under refrigerated vacuum storage $\left(8^{\circ} \mathrm{C}\right)$ for $24 \mathrm{~d}$. A descriptive sensory analysis of taste, smell, and texture, as well as an analysis of acceptability were carried out by a trained panel of 9 judges. No changes were found in cheese strength, sour or buttery odors, nor in acidic or bitter tastes, whereas creamy texture showed a tendency to increase between $\mathrm{d} 8$ and 16 .

The sensory attributes of cheese are the result of diverse factors such as type of milk used, processing conditions, chemical composition, the microflora present, and storage conditions (Delahunty and Drake, 2004). Thus, having the largest amount of information possible on the characteristics of cheese components may help explain the origin of sensory properties. Texture 
profile analysis (Breuil and Meullenet, 2001; Zúñiga et al., 2007) and other instrumental methods can be used to estimate the sensory attributes of cheese; solidphase microextraction (SPME) coupled with GC-MS has been used to analyze the volatile components responsible for aroma (Pinho et al., 2003; Randazzo et al., 2007; Nájera-Domínguez et al., 2014), whereas the effect of fat and moisture content on cheese color can be measured by colorimetry (Manresa and Vicente, 2007). Instrumental methods are of value in establishing correlations with the objective evaluation of judges, as the accuracy and reproducibility achieved by instrumental methods are greater than those achieved by a taste panel (Zamora, 2007) but are no substitute for sensory evaluation (Torricella et al., 2007; Lawless and Heymann, 2010; Stone et al., 2012).

Moreover, sensory specifications are essential to characterize and typify a cheese. In the case of Oaxaca cheese, a sensory profile needs to be developed, as only microbiological and physicochemical specifications are today set down by Mexican legislation (Secretariat of Economy, 2013). In this sense, interest exists from producers and authorities alike in raising the value of food products of Mexican origin. Oaxaca cheese is valuable in cultural terms, as it is a traditional food consumed throughout the country by all social strata. It is also commercially important: 22,061 t was manufactured in 2014, generating an income of Mex $\$ 1,451$ million (SIAP, 2015). Thus, the present study aimed to develop a sensory profile of Oaxaca cheese as well as to examine the relationship between physicochemical parameters and descriptive sensory attributes.

\section{MATERIALS AND METHODS}

\section{Selection and Training}

Panelists were selected and trained according to ISO (2009a). A total of 50 food science students from the Chemistry Department (Universidad Autónoma del Estado de México), aged 19 to $21 \mathrm{yr}$, volunteered to participate in the study. Only 11 were selected, 10 females and 1 male, who achieved a $65 \%$ or higher level of sensory test assertiveness. The training process was complemented with established techniques for the sensory evaluation of cheese (Chamorro and Losada, 2002). Judges were trained in 2 -h sessions over a period of $5 \mathrm{mo}$, for a total of $60 \mathrm{~h}$. Each judge's performance was evaluated by the repeatability index (Biosystems, 2015). A value of $60 \%$ or higher was considered a judge performance validation criterion. Accepted values had a standard deviation of 1.5 or less from 3 replicates of each attribute.

\section{Cheese Manufacture}

Cow milk from the dairy of the Department of Veterinary Medicine and Zootechnics (Universidad Autónoma del Estado de México) was used. Three types of cheese were manufactured in the facilities of the pilot food plant of the Chemistry Department, in 25-kg batches, using a standardized process (ColínCruz et al., 2012) that was carried out at $37^{\circ} \mathrm{C}$ and milk standardized $3.0 \mathrm{~g}$ of fat $/ 100 \mathrm{~g}$; protein content in the milk used was $3.4 \%( \pm 0.05)$. Type 1 cheese $(\mathbf{M C})$, was manufactured using pasteurized milk and mesophilic LAB culture (Lactococcus lactis ssp. lactis and L. lactis ssp. cremoris; R-704, Chr Hansen, Horsholm, Denmark); type 2 cheese (TC), using pasteurized milk and thermophilic LAB culture (Streptococcus salivarius ssp. thermophilus; ST1.14, Chr Hansen); and type 3 cheese (RC), using naturally acidified raw milk. Mesophilic and thermophilic cultures were inoculated at $1 \%$ ( $\mathrm{vol} / \mathrm{vol}$ ). The MC and TC manufacturing processes represent industrially produced Oaxaca cheese, whereas the $\mathrm{RC}$ process is representative of artisanal Oaxaca cheese.

\section{Analyses}

Chemical. Protein was determined by the Kjeldahl method (Secretariat of Economy, 2011), fat content by the Gerber method (Richardson, 1985), moisture content using an atmosphere oven (Richardson 1985), and $\mathrm{pH}$ directly in cheese with a potentiometer (Hanna HI 98140, Hanna Instruments Inc., Woonsocket, RI). Analyses were performed in duplicate (moisture content in triplicate).

Chromatography. The technique used was SPMEGC/MS. Samples (30 g) of shredded Oaxaca cheese were placed in $75-\mathrm{mL}$ glass vials, hermetically sealed, and left for $24 \mathrm{~h}$ at ambient temperature. Prior to analysis, samples were tempered in a double boiler at $45^{\circ} \mathrm{C}$. Volatile compounds were extracted by exposing the divinylbenzene/carboxen/polydimethylsiloxane fiber (Supelco, Bellefonte, PA) for $10 \mathrm{~min}$ in the headspace of the cheese-containing vial while applying ultrasonic agitation. Samples were desorbed in the injection port of the chromatograph at $250^{\circ} \mathrm{C}$ for $1 \mathrm{~min}$ in splitless mode. Volatile compounds were analyzed in a GC (Varian CP-3900, 101909, Varian, Palo Alto, CA) coupled to a mass-selective detector (Varian Saturn 2100T) and separated in an RTX-5MS capillary column (length $30 \mathrm{~m}$, i.d. $0.25 \mathrm{~mm}$, film thickness $0.25 \mu \mathrm{m}$ ) using helium as the carrier gas with a flow rate of $1 \mathrm{~mL} / \mathrm{min}$. The oven temperature program was $15 \mathrm{~min}$ at $40^{\circ} \mathrm{C}$, ramping at $5^{\circ} \mathrm{C} / \mathrm{min}$ to $150^{\circ} \mathrm{C}$, and holding for $3 \mathrm{~min}$. 
The GC-MS transfer line temperature was $150^{\circ} \mathrm{C}$. The mass spectrometer operated with an electron impact energy of $70 \mathrm{eV}$ and a data collection rate of 1 scan per second on a mass-to-charge ratio of 10 to $250 \mathrm{~m} / z$. Volatile compounds in cheese samples were identified by comparing their mass spectra to standard spectra of volatile compounds commonly identified in cheese and to mass spectra in the NIST library (NIST/EPA/NIH Mass Spectral Library, version 2.0, Gaithersburg, MD) of the instrument.

Texture. Textural attributes were measured by the TPA method, using a double compression test. A texturometer (Shimadzu EZ-Test, Kyoto, Japan) was employed, using Rheometer v2.05 software (Shimadzu). Representative samples of each cheese were cut parallel to the longitudinal orientation of fibers into $25 \times$ $25 \times 8 \mathrm{~mm}$ pieces. Cheese temperature at the time of analysis was $16 \pm 2^{\circ} \mathrm{C}$. The test parameters used were ascent velocity $50 \mathrm{~mm} / \mathrm{min}$, descent velocity $50 \mathrm{~mm} /$ min, compression distance $3 \mathrm{~mm}$, recovery time $5 \mathrm{~s}$, and 2 compressions. Attributes measured were firmness, adhesiveness, cohesiveness, gumminess, springiness, and chewiness. Each measurement was performed in sextuplicate on each batch of cheese.

Color. A spectrophotometer (CR-400, Konica Minolta, Ramsey, NJ) with D65 illuminant (corresponding to standard daylight) was used. The color measurement scale employed was Commission International de l'Éclairage (CIE) $L^{*} a^{*} b^{*}$. Color was measured in the 25 $\times 25 \times 8 \mathrm{~mm}$ samples and the reading was taken at an angle of $90^{\circ}$ with regard to the sample. Measurements were made in triplicate.

\section{Sensory Profiling}

Evaluation sessions took place in a Department of Chemistry classroom that was adapted to achieve controlled conditions of a sensory evaluation laboratory: good lighting, adequate ventilation, free of extraneous aromas, noise-free, and with the furniture arranged in a circle for group discussions. Each of the 11 judges selected received a set of the 3 cheeses samples in their characteristic form (a round skein), each weighing approximately $100 \mathrm{~g}$, and identified with a 3-digit random number. The temperature of the cheese at the time of evaluation was $16 \pm 2^{\circ} \mathrm{C}$. The evaluation process was carried out in 8 sessions, with an average duration of 3 h (ISO, 2003, 2009b). Sensory evaluation of the cheeses was done in the following sense perceptions: visual (appearance), tactile (manual texture), olfactory (orthonasal and retronasal aroma), basic taste (tongue), mouthfeel (mouth texture), and auditory (hearing). Attributes representative of each cheese were identified and described, techniques for evaluating each attribute were established, and the physical reference products per attribute were agreed upon. After the sample evaluation protocol was established with the judges, individual cheese attributes were quantified using a continuous 10-cm line scale, marked from 0 to 9 to aid capture of in-between intensity values $(0=$ attribute not present,

Table 1. Mean chemical composition, instrumental texture values, and CIE $L^{*} a^{*} b^{*}$ scale color parameters in Oaxaca cheese

\begin{tabular}{lccc}
\hline & \multicolumn{3}{c}{ Cheese type $^{1}$} \\
\cline { 2 - 4 } Item & TC & MC & RC \\
\cline { 2 - 4 } Chemical composition & $53.78 \pm 0.34^{\mathrm{a}}$ & $52.45 \pm 0.02^{\mathrm{b}}$ & $51.16 \pm 0.07^{\mathrm{c}}$ \\
Moisture (\%) & $22.18 \pm 0.73$ & $22.57 \pm 0.54$ & $22.87 \pm 0.29$ \\
Protein (\%) & $20.41 \pm 0.21^{\mathrm{b}}$ & $22 \pm 0.1^{\mathrm{a}}$ & $21.75 \pm 0.35^{\mathrm{a}}$ \\
Fat (\%) & $5.25 \pm 0.10^{\mathrm{a}}$ & $5.37 \pm 0.11^{\mathrm{a}}$ & $5.04 \pm 0.17^{\mathrm{b}}$ \\
pH & & & \\
Texture characteristics & $22.25 \pm 5.47^{\mathrm{a}}$ & $23.99 \pm 5.21^{\mathrm{a}}$ & $33.45 \pm 4.63^{\mathrm{b}}$ \\
Firmness (N) & $-1.1 \pm 0.23^{\mathrm{b}}$ & $-0.59 \pm 0.09^{\mathrm{a}}$ & $-0.57 \pm 0.14^{\mathrm{a}}$ \\
Adhesiveness (N) & $0.12 \pm 0.06$ & $0.15 \pm 0.05$ & $0.28 \pm 0.04$ \\
Cohesiveness & $251.31 \pm 112.87^{\mathrm{a}}$ & $298.75 \pm 185.79^{\mathrm{a}}$ & $746.68 \pm 182.41^{\mathrm{b}}$ \\
Gumminess & $0.42 \pm 0.06$ & $0.48 \pm 0.04$ & $0.50 \pm 0.06$ \\
Springiness & $105.86 \pm 56.53^{\mathrm{a}}$ & $143.63 \pm 92.52^{\mathrm{a}}$ & $375.03 \pm 91.03^{\mathrm{b}}$ \\
Chewiness & & & \\
Cheese color parameters & & $87.51 \pm 0.74^{\mathrm{a}}$ & $85.72 \pm 0.47^{\mathrm{b}}$ \\
$L$ & $86.6 \pm 2.08^{\mathrm{b}}$ & $-8.34 \pm 1.56$ & $-8.55 \pm 1.49$ \\
$a^{*}$ & $-8.43 \pm 1.56$ & $27.99 \pm 1.96$ & $29.69 \pm 0.90$ \\
$b^{*}$ & $26.88 \pm 1.54$ & $71.68 \pm 1.29$ & $69.96 \pm 0.22$ \\
WI & $71.94 \pm 1.57$ & & \\
\hline
\end{tabular}

${ }^{\mathrm{a}-\mathrm{c}}$ Different superscript letters within an attribute mean values differ significantly among samples $(P \leq 0.05)$.

${ }^{1} \mathrm{TC}=$ cheese manufactures with thermophilic $\mathrm{LAB}$ culture; $\mathrm{MC}=$ with mesophilic $\mathrm{LAB} ; \mathrm{RC}=$ with raw milk.

${ }^{2} L=$ lightness; $a^{*}=$ redness; $b^{*}=$ yellowness; $\mathrm{WI}=$ white index. 
$1=$ minimum intensity, $9=$ maximum intensity). The relative intensity of each attribute (expressed as the mean value obtained from 11 judges in 3 replicates) per cheese was used to graph the 3 descriptive profiles. Variability among judges was determined by evaluating 1 batch of cheese in triplicate on the same day, whereas variability among samples was determined by evaluating 3 different batches of cheese on different days.

\section{Statistical Analysis}

To determine specific differences between the 3 cheeses, each attribute was analyzed by ANOVA and a
Fisher test. Principal component analysis was used to find correlations between sensory attributes and instrumental and physicochemical parameters. Sensory data input was achieved with the portable version of Fizz software and data analysis with Fizz Calculations v2.50 (Biosystemes, Couternon, France).

\section{RESULTS AND DISCUSSION}

\section{Chemical Composition of Cheese}

Moisture content was highest in the cheese made with a thermophilic LAB culture (TC), medium in the

Table 2. Mean values of Oaxaca cheese sensory attributes $(n=11 \text { judges with } 3 \text { replicates })^{1}$

\begin{tabular}{|c|c|c|c|c|}
\hline Sense perception/organ & Descriptive attribute & $\mathrm{TC}$ & $\mathrm{MC}$ & $\mathrm{RC}$ \\
\hline Visual & Round skein & 7.4 & 7.49 & 7.58 \\
\hline \multirow[t]{7}{*}{ (appearance) } & Pale yellow & 7.11 & 7.59 & 7.28 \\
\hline & Shiny & 5.86 & 6.12 & 6.54 \\
\hline & Waxy & $5.61^{\mathrm{b}}$ & $6.61^{\mathrm{a}}$ & $5.68^{\mathrm{b}}$ \\
\hline & Moist & 5.43 & 5.11 & 5.68 \\
\hline & Springy & 5.46 & 5.45 & 5.68 \\
\hline & Striated & 5.10 & 4.94 & 5.52 \\
\hline & Fatty & 5.17 & 5.89 & 4.98 \\
\hline Tactile & Rugose & 4.46 & 4.46 & 5.08 \\
\hline \multirow{4}{*}{ (manual texture) } & Moist & $5.21^{\mathrm{b}}$ & $5.07^{\mathrm{b}}$ & $6.02^{\mathrm{a}}$ \\
\hline & Oily & $5.24^{\mathrm{b}}$ & $6.01^{\mathrm{a}}$ & $4.94^{\mathrm{b}}$ \\
\hline & Springy & 5.77 & 5.55 & 5.16 \\
\hline & Shreddable & 6.94 & 6.69 & 6.76 \\
\hline Olfactory & Sour milk & 4.67 & 4.69 & 5.54 \\
\hline \multirow{7}{*}{ (orthonasal aroma) } & Boiled milk & 5.38 & 5.28 & 5.21 \\
\hline & Butyric acid & 3.78 & 3.83 & 3.65 \\
\hline & Empyreumatic & $3.30^{\mathrm{b}}$ & $3.74^{\mathrm{a}}$ & $2.92^{\mathrm{c}}$ \\
\hline & Oleic acid & 2.88 & 3.30 & 3.28 \\
\hline & Cow & $3.30^{\mathrm{b}}$ & $2.77^{\mathrm{c}}$ & $3.75^{\mathrm{a}}$ \\
\hline & Diacetyl & 4.13 & 4.08 & 3.60 \\
\hline & $\delta$-Decalactone & 3.78 & 3.51 & 3.46 \\
\hline Olfactory & Boiled milk & 5.21 & 5.36 & 5.27 \\
\hline \multirow[t]{6}{*}{ (retronasal aroma) } & Butyric acid & 3.74 & 3.63 & 3.78 \\
\hline & Almond & 3.00 & 2.95 & 2.94 \\
\hline & Empyreumatic & 3.43 & 3.58 & 3.43 \\
\hline & Cow & 3.48 & 3.33 & 3.82 \\
\hline & Diacetyl & 4.19 & 4.13 & 3.74 \\
\hline & Sour milk & 4.63 & 3.98 & 4.79 \\
\hline \multirow[t]{4}{*}{ Basic taste (tongue) } & Sweet & 4.87 & 5.08 & 4.77 \\
\hline & Salty & $4.96^{\mathrm{c}}$ & $5.70^{\mathrm{b}}$ & $6.43^{\mathrm{a}}$ \\
\hline & Sour & 4.79 & 4.65 & 4.71 \\
\hline & Bitter & 3.18 & 3.23 & 2.89 \\
\hline \multirow[t]{10}{*}{ Mouthfeel (mouth texture) } & Firm & 5.30 & 5.49 & 5.83 \\
\hline & Crumbly & 3.18 & 3.90 & 3.23 \\
\hline & Chewable & $5.41^{\mathrm{b}}$ & $5.17^{\mathrm{b}}$ & $6.37^{\mathrm{a}}$ \\
\hline & Gummy & $4.45^{\mathrm{b}}$ & $4.65^{\mathrm{b}}$ & $5.71^{\mathrm{a}}$ \\
\hline & Viscous & 5.39 & 5.41 & 5.16 \\
\hline & Adherent & $3.97^{\mathrm{a}}$ & $4.07^{\mathrm{a}}$ & $3.39^{\mathrm{b}}$ \\
\hline & Grainy & 2.79 & 3.10 & 2.82 \\
\hline & Fibrous & $4.34^{\mathrm{b}}$ & $4.69^{\mathrm{b}}$ & $5.62^{\mathrm{a}}$ \\
\hline & Moist & $4.95^{\mathrm{b}}$ & $4.80^{\mathrm{b}}$ & $5.57^{\mathrm{a}}$ \\
\hline & Fatty & $5.17^{\mathrm{b}}$ & $5.63^{\mathrm{a}}$ & $4.71^{\mathrm{c}}$ \\
\hline Auditory (hearing) & Squeaky & $4.68^{\mathrm{b}}$ & $4.34^{\mathrm{b}}$ & $6.13^{\mathrm{a}}$ \\
\hline
\end{tabular}


cheese with a mesophilic LAB culture (MC), and lowest in the cheese using raw milk (RC); these values were significantly different $(P<0.05$; Table 1$)$. The mean time of acidification required to reach kneading $\mathrm{pH}(5.3-5.2)$ varied depending on the starter culture used: $187( \pm 45), 227( \pm 18)$, and $288( \pm 13) \mathrm{min}$, respectively, for RC, TC, and MC. Thermophilic LAB (S. salivarius ssp. thermophilus) multiply rapidly and acidify milk (Iyer et al. 2009) in a shorter time than mesophilic LAB (L. lactis ssp. lactis and L. lactis ssp. cremoris). As a result, processing time is longer when a mesophilic starter culture is used, syneresis is greater, and the cheese retains less moisture, whereas fat and protein content increase (Table 1). In cheese manufactured with raw milk, the lactic flora comprises a wide variety of thermophilic and mesophilic LAB (Caro et al., 2013), which together acidify milk even more rapidly and speed up syneresis, expelling a large quantity of serum (Liu et al., 2014) and resulting in a low-moisture cheese.

\section{Instrumental TPA}

Comparison of cheese instrumental texture using a texturometer (TPA) indicates that firmness, gumminess, and chewiness were highest in RC cheese, followed by MC and TC cheeses (Table 1), whereas adhesiveness was highest in TC. No significant differences were found between the cheeses in terms of cohesiveness and springiness; this behavior of texture parameters may due to the moisture content of the different cheeses. Expulsion of water during the manufacturing process favors protein-protein interaction, which results in a more compact protein matrix (Zisu and Shah, 2005). If the curd is stirred for a longer time during acidification, more whey is expelled and the resulting cheese

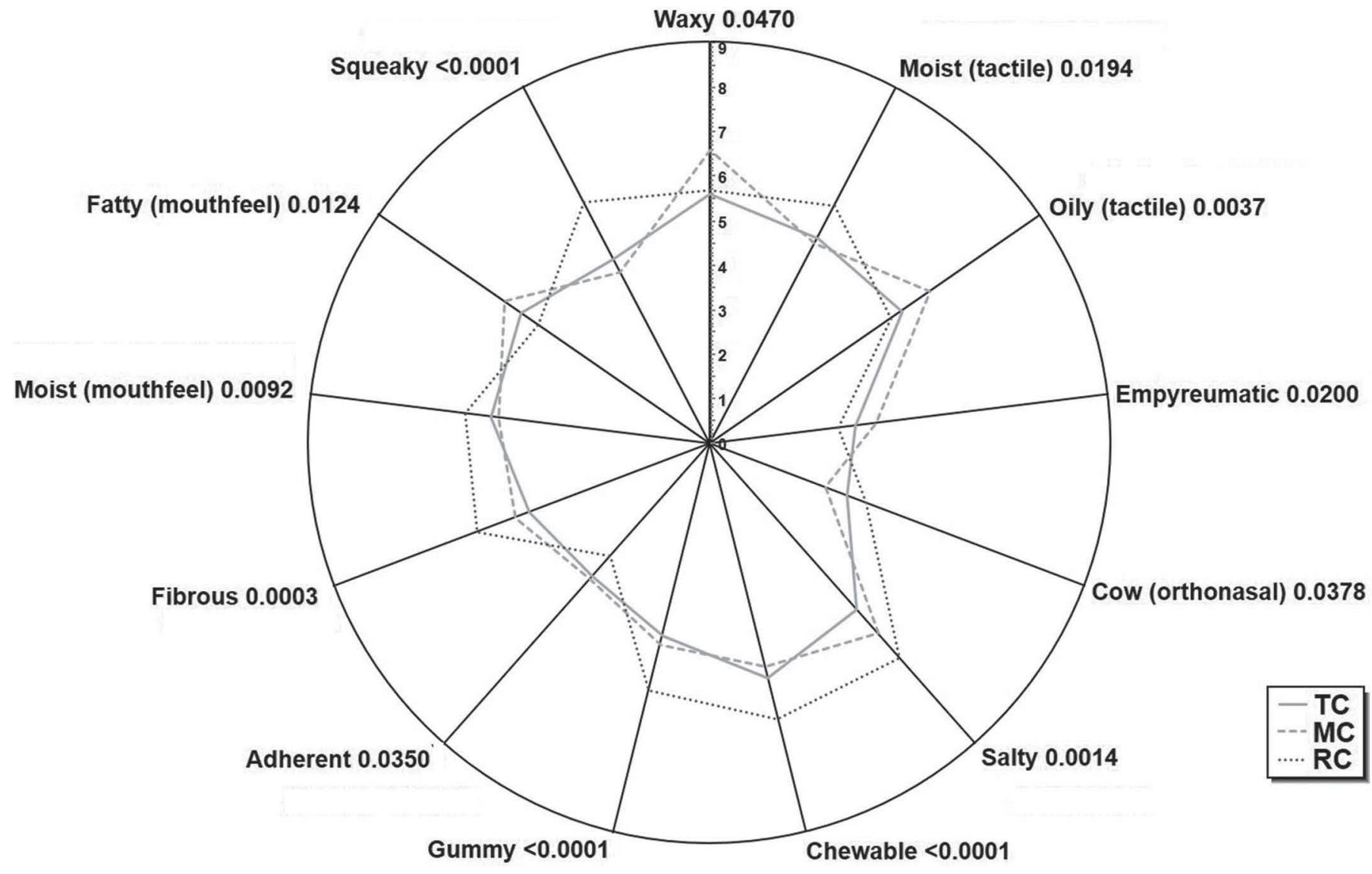

Figure 1. Graphic representation of the descriptive sensory profiles of 3 Oaxaca cheeses, showing only 13 discriminant attributes (n $=11$ judges with 3 replicates). TC = cheese manufactured with Streptococcus salivarius ssp. thermophilus (ST1.14, Chr. Hansen, Hørsholm, Denmark); $\mathrm{MC}=$ cheese manufactured with Lactococcus lactis ssp. lactis and L. lactis ssp. cremoris (R-704, Chr. Hansen); RC = cheese manufactured with naturally acidified raw milk. 
will have a low moisture content (Irigoyen et al., 2002; Everard et al., 2007) and will be more firm and more compact. Thus, in the cheeses evaluated in the present study, moisture content was inversely proportional to firmness, gumminess, and chewiness, but directly proportional to adhesiveness.

\section{Cheese Colorimeter Parameters}

Table 1 shows the CIE $L^{*} a^{*} b^{*}$ colorimeter scale parameters for the cheeses under study. The characteristic color of cheese is due to the dispersal of light caused by fat globules, casein micelles, and colloidal calcium phosphate, although carotene and riboflavin also contribute to this effect (Kristensen et al., 2001; Mortensen et al., 2003). The resulting combination of chromatic coordinates shows that Oaxaca cheeses have pale yellow tonalities. Whiteness index values were higher in $\mathrm{TC}$ than in $\mathrm{MC}$ and $\mathrm{RC}$ cheeses, although significant differences among the cheeses were not found.

\section{Sensory Profile Development}

Once the panel generated, defined, and obtained physical descriptive attribute references, established sensory evaluation protocols, and the specific 43 attribute perceptual intensities were agreed upon for the Oaxaca cheese, then the descriptive profile could be defined. The descriptive attributes were grouped according to its perception sense organ as follows: 8 visual (appearance), 5 tactile (manual texture), 15 nasal (aroma: 8 orthonasal, 7 retronasal), 4 basic taste (tongue), 10 mouthfeel (mouth texture), and 1 auditory (ear; Table 2).

Some of the attributes described in our study are consistent with results obtained in previous artisanal Oaxaca cheese studies. Montes de Oca-Flores et al. (2012) found sour and salty as major attributes, whereas Fuentes et al. (2015) described sour and buttery odors and acidic taste.

Among the 3 types of cheese in our study, only 13 attributes were discriminant $(P \leq 0.05)$ : waxy (visual); moist and oily (tactile); empyreumatic and cow (orthonasal aroma); salty (basic taste); chewable, gummy, adherent, fibrous, moist, and fatty (mouth texture); and squeaky (auditory; Table 2 and Figure 1). The discriminant attributes perceived with greater intensity in $\mathrm{RC}$ cheese were moist (tactile), cow (orthonasal), salty, chewable, gummy, fibrous, moist (mouthfeel), and squeaky (auditory); whereas in MC cheese the most intense were waxy, oily, empyreumatic, adherent, and fatty. In TC, not one attribute was perceived to be of high intensity; on the contrary, this cheese is characterized by the lowest intensity in the attributes waxy, salty, gummy, and fibrous.

\section{Sensory Judge Test Performance}

The repeatability performance of the panel members ranged from 63.7 to $99.3 \%$. Thus, the 11 selected judges were considered a valid panel.

\section{Aromatic Chemical Compounds and Relationship with Sensory Attributes}

The characteristic flavor of each variety of cheese is the result of a complex balance between volatile and nonvolatile chemical compounds produced during the manufacturing process from the fats, proteins, and carbohydrates present in milk (Fox and Wallace, 1997). In the present study, SPME-GC/MS helped us to identify 11 volatile compounds present in the 3 cheeses (Table 3), 2 additional compounds were detected in MC cheese (2-nonanone and ethyl acetate), and 1 more in $\mathrm{RC}$ cheese (ethanol). The identification of these few compounds may be attributed to the fact that the 3 cheeses

Table 3. Volatile compounds identified in Oaxaca cheeses by solid-phase microextraction coupled with GC-MS and olfactory notes evoked

\begin{tabular}{llll}
\hline & $\begin{array}{c}\text { Retention } \\
\text { time } \\
\text { Peak }\end{array}$ & Compound & Olfactory note \\
\hline 1 & 1.016 & 2-Methyl propanoic acid & Rancid, cheese, butter \\
2 & 1.078 & 2-Propanone & Cowshed \\
3 & 1.112 & 2-Butanone & Butter, milky, creamy \\
4 & 1.650 & 3-Methyl-2-pentanone & Fruity, ether, acetone \\
5 & 1.665 & 3-Methyl-butanal & Rancid, putrid \\
6 & 1.711 & 2-Heptanone & Fruity, banana, floral \\
7 & 2.369 & 3-Hydroxy-2-butanone (acetoin) & Butter \\
8 & 2.558 & Butanodione (diacetyl) & Butter, popcorn, cheese \\
9 & 3.680 & Acetic acid & Vinegar, pungent \\
10 & 3.869 & Propanoic acid & Cheese, milk, butter, fruity, pungent \\
11 & 4.804 & Butanoic acid, propyl ester & Fruitlike \\
\hline
\end{tabular}


were analyzed $1 \mathrm{~d}$ after their manufacture. In ripened cheeses (Pinho et al., 2003; Randazzo et al., 2007), a large number of volatile compounds have been reported due to degradation of cheese components during the ripening period. The 11 molecules detected in Oaxaca cheese are among those reported in the cited reviews.

In the olfactory (ortho- and retronasal) evaluation of Oaxaca cheese, the panel identified 9 attributes (Table 2) that are probably related to the 11 volatile compounds detected by chromatography (Table 3). These attributes were perceived with different degrees of intensity in each cheese, although only empyreumatic (associated with cooked milk) and cow exhibited significant differences. The attributes perceived with greater intensity among the 3 cheese types were diacetyl and $\delta$-decalactone in TC; empyreumatic and oleic acid in MC; and acidified lactic and cow in RC. These olfactory attributes can be associated with the following instrumentally detected aromatic notes (Table 3): butanedione relates to diacetyl; 3-methyl-2-pentanone and 2-heptanone relate to $\delta$-decalactone; 2-butanone relates to empyreumatic; 2-methyl propanoic acid and 3-methyl-butanal relate to oleic acid; 2-methyl propanoic acid, acetic acid, and propanoic acid relate to acidified lactic; and 2-propanone and 3-methyl-butanal relate to cow.

Regarding the 2 attributes with significant differences, cow was perceived more intensely in $\mathrm{RC}$ than in $\mathrm{TC}$ and MC cheeses. This attribute may be associated with coliform bacteria that are always present in artisanal Oaxaca cheese. In a study of artisanal Oaxaca cheese by Villanueva-Carvajal et al. (2012), cow was perceived as one of the most intense attributes. In our study, empyreumatic was perceived with greater intensity in $\mathrm{MC}$ and TC cheeses, an attribute that might be associated with pasteurization notes.

\section{Sensory and Instrumental Correlation}

Of the 43 descriptive sensory attributes, without taking into account cheese type, 14 attributes were strongly correlated $(\geq 0.70)$ with physicochemical and instrumental parameters (Table 4). Ten of these attributes were discriminant and 4 were nondiscriminant between the 3 cheeses.

Among the physicochemical characteristics shown in Table 4, moisture content had a strong negative correlation with the sensory attributes firm, chewable, and gummy ( $\mathrm{r}=-0.81,-0.94$, and -0.98 , respectively), which may lead to understand that as perception of these attributes increases, moisture decreases. This is consistent with the correlation between moisture content and texture parameters such as firmness, gumminess, and chewiness, which, as stated above, are per-

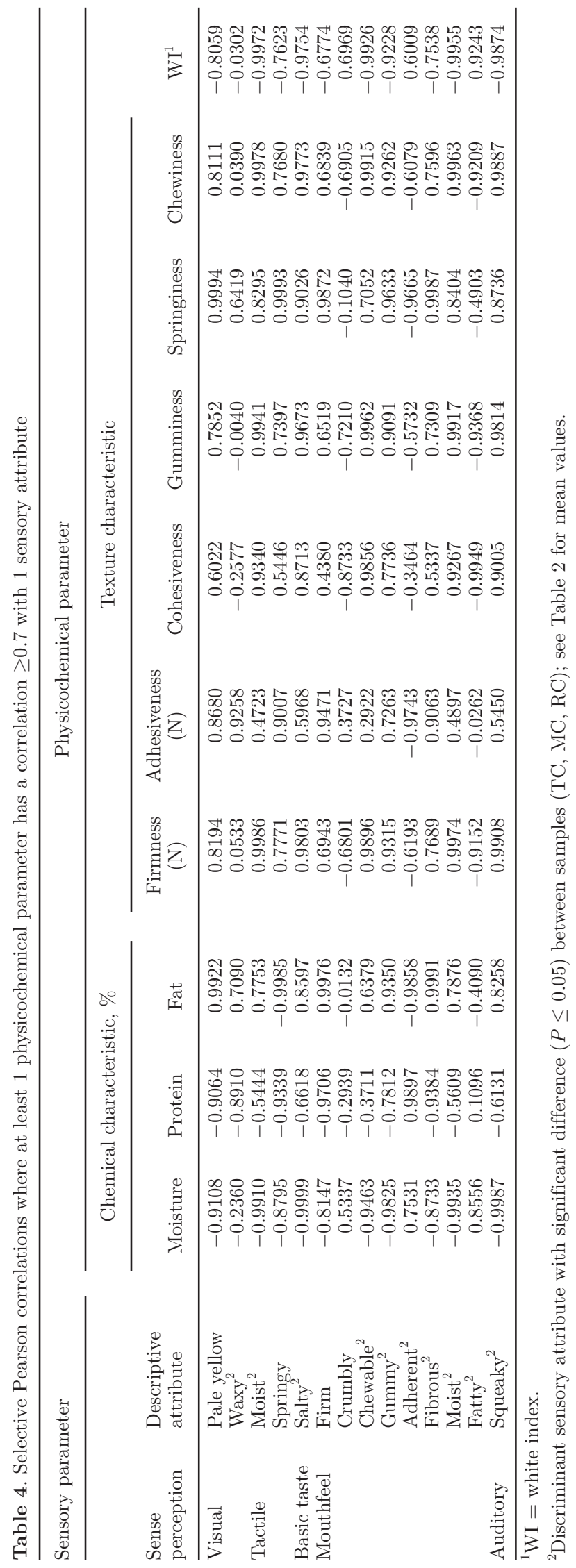

Journal of Dairy Science Vol. 99 No. 9, 2016 


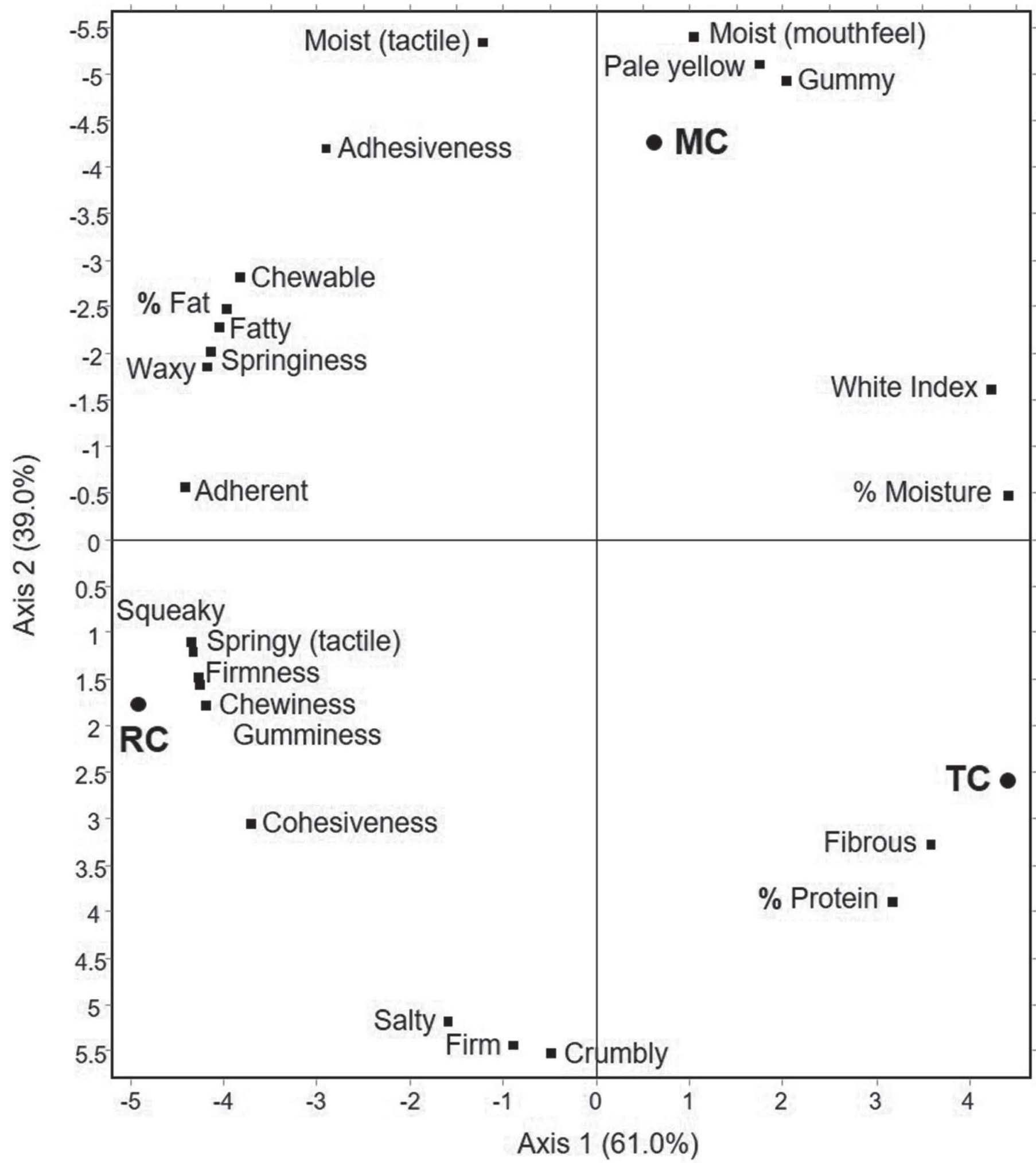

Figure 2. Principal component analysis of 3 Oaxaca cheeses, showing the sensory attributes and the Physicochemical mean values from Table 4. TC $=$ cheese manufactured with Streptococcus salivarius ssp. thermophilus (ST1.14, Chr. Hansen, Hørsholm, Denmark); MC = cheese manufactured with Lactococcus lactis ssp. lactis and L. lactis ssp. cremoris (R-704, Chr. Hansen); RC = cheese manufactured with naturally acidified raw milk. 
ceived more intensely as moisture decreases. The strong negative correlation between moisture content and the attribute moist (tactile and mouthfeel; $\mathrm{r}=-0.99$ and -0.99 , respectively) is surprising. A positive correlation would be expected, but the moist scale structure assigns a high value to a lowest-moisture content cheese, thus explaining this negative correlation (Tables 1 and 2).

The strong negative correlation $(\mathrm{r}=-0.99)$ between moisture content and the attribute salty is remarkable; it is consistent with the result in Table 2, in which the cheese with the lowest moisture content (Table 1) obtained the highest value for the attribute salty (Table 2). A strong correlation exists between the physicochemical parameter fat content and the attributes pale yellow $(r=0.99)$ and waxy $(r=0.70)$. This is consistent with results in Tables 1 and 2, which show that the cheese with a higher fat content obtained the highest values for these sensory attributes.

With regard to TPA characteristics, a clear, strong correlation was noted with the corresponding sensory attributes. The strong positive correlation $(r \geq 0.90)$ between firmness and the sensory attributes chewable, gummy, and squeaky make sense, as in cheeses that were more firm (Table 1) these attributes were perceived with greater intensity (Table 2). Surprisingly, the correlation between firmness and the attribute firm was rather low $(r=0.69)$. The negative value found for the correlation between adhesiveness and the attribute adherent $(\mathrm{r}=-0.97)$ seems incongruent, but is explained by the negative value for this parameter provided by the texturometer (Table 1 ).

Gumminess and chewiness were strongly correlated with the corresponding sensory attributes gummy and chewable $(\mathrm{r}=0.90$ and 0.99 , respectively). Both texture parameters show a similar behavior and were strongly correlated $(\mathrm{r}>0.70)$ with some sensory attributes related to cheese texture, such as chewable, fibrous, moist, and squeaky (Table 2). Springiness was strongly correlated with springy $(\mathrm{r}=0.99)$, whereas cohesiveness showed a strong negative correlation $(\mathrm{r}=$ $-0.87)$ with crumbly.

Principal component analysis (Figure 2) indicates that milk treatment (raw vs. pasteurized) accounted for $61 \%$ of the variance: the cheese made from raw milk is on the left side of the plot and the cheeses made from pasteurized milk are on the right side. Starter accounted for $39 \%$ of the variance: in the upper right quadrant is cheese made with a mesophilic culture; in the lower left quadrant is cheese made using a natural acidification; and in the lower right quadrant is cheese made with a thermophilic culture. The principal component analysis reflects the attributes that characterize or correlate with each cheese: boiled milk (retronasal), empyreumatic (ortho- and retronasal), sweet, fatty (vi- sual and mouth texture), and crumbly in MC cheese; shiny, striated, cow (ortho- and retronasal), salty, firm, chewable, gummy, and squeaky in RC cheese; and $\delta$-decalactone, viscous, and adherent in TC cheese.

The study revealed few significant differences among these cheeses in physicochemical and instrumental parameters (6 out of 11) and sensory attributes (13 out of 43). Nevertheless, these differences helped distinguish each cheese and allowed us to typify them on the basis of these physicochemical and sensory terms. It was also observed that the cheese could be more fully characterized at the sensory level than at the physicochemical or instrumental levels due to the variety of attributes. Furthermore, a strong correlation is demonstrated between physicochemical and instrumental parameters and sensory evaluation, as physicochemical results were confirmed by sensory evaluation. Thus, both methods of evaluation are coherent and complement each other.

\section{CONCLUSIONS}

The sensory panel defined 43 attributes common to 3 Oaxaca cheeses. A total of 13 attributes contributed significantly to discrimination of the 3 cheeses evaluated in sensory terms. The sensory vocabulary proposed in this research could encompass the sensory characteristics of industrial as well as artisanal Oaxaca cheese. The study revealed a strong overall correlation between the physicochemical parameters evaluated in the cheeses and the sensory attributes described by the panel. The profile developed may serve as a reference to evaluate the sensory characteristics of commercial cheeses made by industrial or artisanal processes and may also contribute to establishing a standard that takes sensory characteristics into consideration as a quality parameter in Oaxaca cheese.

\section{ACKNOWLEDGMENTS}

This study was financially supported by PROMEPSEP (Programa de Mejoramiento del Profesorado-Secretaría de Educación Pública, Government of Mexico, Mexico City, Mexico) through Project UAEM-CA-181. The authors are grateful to Magdalena Fabila García (Universidad Autonoma del Estado de Mexico, Mexico City, Mexico) for assistance with chromatography experiments and to Ivan Mendez at Pentasensorial Co. for help with statistical analyses using FIZZ software. We also thank all members of the sensory panel.

\section{REFERENCES}

Biosystems. 2015. FIZZ Calculations, Reference manual. Version 2.50, France. Revision: May 6, 2015. Biosystems, Couternon, France 
Breuil, P., and J. Meullenet. 2001. A comparison of three instrumental tests for predicting sensory texture profiles of cheese. J. Texture Stud. 32:41-55.

Caro, I., J. Mateo, M. H. Sandoval, S. Soto, M. García-Armesto, and J. M. Castro. 2013. Characterization of Oaxaca raw milk cheese microbiota with particular interest in Lactobacillus strains. J. Dairy Sci. 96:3461-3470.

Chamorro, M. C., and M. M. Losada. 2002. El Análisis Sensorial de los Quesos. Mundi Prensa, Spain.

Colín-Cruz, M. A., O. Dublán-García, A. Espinoza-Ortega, and A. Domínguez-López. 2012. The effect of varying fat content on the microstructure of Oaxaca cheese, a typical pasta filata cheese. Int. J. Dairy Technol. 65:71-80.

Delahunty, C. M., and M. A. Drake. 2004. Sensory character of cheese and its evaluation. Pages 455-473 in Cheese, Chemistry Physics and Microbiology. 3rd ed. Vol. 2. F. Fox, P. Mcsweeney, T. Cogan, and P. Guinee, ed. Elsevier Academic Press, Cambridge, MA.

Everard, C. D., D. J. O'Callaghan, B. T. O'Kennedy, C. P. O'Donnell, E. M. Sheehan, and C. M. Delahunty. 2007. A three-point bending test for prediction of sensory texture in processed cheese. J. Texture Stud. 38:438-456.

Fox, P. F., and J. M. Wallace. 1997. Formation of flavour compounds in cheese. Adv. Appl. Microbiol. 45:17-85.

Fuentes, L., J. Mateo, J. Q. Emiliano, and I. Caro. 2015. Changes in quality of nonaged pasta filata Mexican cheese during refrigerated vacuum storage. J. Dairy Sci. 98:2833-2842.

Irigoyen, A., M. Castiella, A. I. Ordonez, P. Torre, and F. C. Ibarez. 2002. Sensory and instrumental evaluations of texture in cheeses made from ovine milks with differing fat contents. J. Sens. Stud. $17: 145-161$.

ISO. 2003. ISO 13299:2003. Sensory analysis-Methodology-General guidance for establishing a sensory profile. International Organization for Standardization (ISO), Geneva, Switzerland.

ISO. 2009a. ISO 22935-1/IDF 99-1:2009. Milk and milk productsSensory analysis - Part 1: General guidance for the recruitment, selection, training and monitoring of assessors. International Dairy Federation, Brussels, Belgium.

ISO. 2009b. ISO 22935-2/IDF 99-2:2009 Milk and milk productsSensory analysis - Part 2: Recommended methods for sensory evaluation. International Dairy Federation, Brussels, Belgium.

Iyer, R., S. K. Tomar, T. U. Maheswari, and R. Singh. 2009. Streptococcus thermophilus strains: Multifunctional lactic acid bacteria. Int. Dairy J. 20:133-141.

Kristensen, D., E. Hansen, A. Arndal, R. Appelgren, R. A. Trinderup, and L. H. Skibsted. 2001. Influence of light and temperature on the color and oxidative stability of processed cheese. Int. Dairy J. 11:837-843.

Lawless, H. T., and H. Heymann. 2010. Sensory Evaluation of Food. Principles and Practices. 2nd ed. Springer, New York, NY.

Liu, X. T., H. Zhang, H. F. Wang, J. Luo, H. Y. Guo, and F. Z. Ren. 2014. Rheological and structural properties of differently acidified and renneted milk gels. J. Dairy Sci. 97:3292-3299.

Manresa, G. A., and I. Vicente. 2007. El Color en la Industria de Alimentos. Editorial Universitaria, Havana, Cuba.

Montes de Oca-Flores, E., O. Castelán-Ortega, J. G. Estrada-flores, and A. Espinoza-Ortega. 2009. Oaxaca cheese: Manufacture process and physicochemical characteristics. Int. J. Dairy Technol. $62: 535-540$.
Montes de Oca-Flores, E., C. M. Jordán, Á. R. M. Campos, and A. Ortega. 2012. Perfil sensorial del queso Oaxaca tradicional en el Altiplano central de México. Page 183 in 13 Congreso Nacional de Investigación Socioeconómica y Ambiental de la Producción Pecuaria. Accessed Oct. 10, 2015. https://www.researchgate.net/ profile/Octavio_393 Barrera-Perales/publication/273693452_13_ Congreso_Socioeconomia_Ambiental_394Pecuaria/ links/5508934a0cf26ff55f836248.

Mortensen, G., G. Bertelsen, B. K. Mortensen, and H. Stapelfeldt 2003. Light-induced changes in packaged cheeses-A review. Int Dairy J. 14:85-102.

Nájera-Domínguez, C., N. Gutiérrez-Méndez, G. Nevárez-Moorillon, and I. Caro-Canales. 2014. Comparison of volatile compounds produced by wild Lactococcus lactis in miniature Chihuahua-type cheeses. Dairy Sci. Technol. 94:499-516.

Secretariat of Economy. 2011. NMX-F-608-NORMEX-2011. Alimentos. Determinación de proteínas en alimentos. Comité Técnico de Normalización Nacional para la Industria Alimentaria (NALI-10), Mexico City, México.

Secretariat of Economy 2013. NMX-F-733-COFOCALEC-2013 Sistema producto leche-alimentos-lácteos-queso Oaxaca-denominación, especificaciones y métodos de prueba. Organismo Nacional de Normalización del COFOCALEC, Mexico City, México.

Pinho, O., C. Pérès, and I. M. P. L. V. O. Ferreira. 2003. Solid-phase microextraction of volatile compounds in Terrincho ewe cheese. Comparison of different fibers. J. Chromatogr. A 1011:1-9.

Randazzo, C. L., S. De Luca, A. Todaro, C. Restuccia, C. M. Lanza, G. Spagna, and C. Caggia. 2007. Preliminary characterization of wild lactic acid bacteria and their abilities to produce flavour compounds in ripened model cheese system. J. Appl. Microbiol. 103:427-435.

Richardson, G. H. 1985. Standard Methods for the Examination of Dairy Products. 15th ed. Am. Publ. Health Assoc., Washington, DC.

SIAP. 2015 Boletín de leche. Octubre-Diciembre, Servicio de Información Agroalimentaria y Pesquera, Accessed Apr. 26, 2016. http://www.siap.gob.mx/wp-content/uploads/boletinleche/b_ leche_oct_dic_2015.pdf.

Stone, H., R. Bleibaum, and H. Thomas. 2012. Sensory Evaluation Practices. 4th ed. Academic Press, Cambridge, MA.

Torricella, R., E. Zamora, and H. Pulido. 2007. Evaluación Sensorial Aplicada a la Investigación, Desarrollo y Control de la Calidad en la Industria Alimentaria. Editorial Universitaria, Havana, Cuba.

Villanueva-Carvajal, A., M.A. Esteban-Chávez, A. Espinoza-Ortega, C.M. Arriaga-Jordán, and A. Dominguez-López. 2012. Oaxaca cheese: Flavour, texture and their interaction in a Mexican traditional pasta filata type cheese. CyTA J. Food 10:63-70.

Zamora, E. 2007. Evaluación Objetiva de la Calidad Sensorial de Alimentos procesados. Editorial Universitaria, Havana, Cuba.

Zisu, B., and N. P. Shah. 2005. Textural and functional changes in lowfat Mozzarella cheeses in relation to proteolysis and microstructure as influenced by the use of fat replacers, pre-acidification and EPS starter. Int. Dairy J. 15:957-972.

Zúñiga, H., V. Ciro, and S. Osorio. 2007. Study of Edam cheese hardness using texture profile analysis and penetrometry by sphere. Rev. Fac. Nac. Agron. (Medellin) 60:1-14. 